\title{
Unveiling Solid State Dissimilar Ni-base Alloy 625 and Structural Steel Joints Using Transmission Kikuchi Diffraction
}

\author{
Genevieve Lee ${ }^{1}$, Jonathan Orsborn ${ }^{2,3}$, Antonio Ramirez ${ }^{1}$ \\ 1. Welding Eng. Program, Dept. of Materials Science and Eng., The Ohio State University - Columbus, \\ $\mathrm{OH}, \mathrm{USA}$ \\ 2. Center for Electron Microscopy, Dept. of Materials Science and Eng., The Ohio State University - \\ Columbus, $\mathrm{OH}$, USA \\ 3. Center for the Accelerated Maturation of Materials, Dept. of Materials Science and Eng., The Ohio \\ State University, Columbus, $\mathrm{OH}$, USA
}

Dissimilar joints involving Ni-based alloys and structural steels are commonly used in applications where cost effective solutions require excellent corrosion and oxidation resistance at ambient or elevated temperatures. Industries working with pressure vessels, power generation, and oil and gas production and transformation often use a combination of such materials. They hold and transport corrosive, even caustic fluids at high pressures and sometimes temperatures, commonly within marine environments. Fusion welds between the two materials often present metallurgical issues, such as cracking, porosity, and embrittlement. On the other hand, solid state joining provides high quality joints while circumventing material melting and solidification. Solid state joining eliminates flaws inherent to the fusion process, but also introduces new weldability challenges. Friction Stir Welding (FSW) is a wellestablished solid-state joining technique used in manufacturing where a non-consumable tool is plunged into a lap or butt joint to heat and plasticize the material around it to induce material flow. The resulting bond between parts generally has remarkable metallurgical and physical properties. This study analyzes the friction stir joints interfaces between A516 low-carbon steel and Ni-alloy 625 using Transmission Kikuchi Diffraction (TKD) and Energy Dispersive X-Ray Spectroscopy (XEDS). The joint microstructure adjacent to the weld interface is evaluated at high spatial resolutions using such tools.

Ni-based alloy 625 and low carbon steel A516 plates were friction welded with a composite W-Re matrix tool reinforced with cubic boron nitride [1]. A cross section of the weld interface was used for bulk analysis of the joint. The nickel and steel stir zones $\left(\mathrm{SZ}_{625}\right.$ and $\left.\mathrm{SZ}_{\mathrm{A516}}\right)$ at the interface region were characterized using optical microscopy (OM) and scanning electron microscopy (SEM) with TKD and XEDS. Thin foils approximately $40 \mu \mathrm{m}$ by $5 \mu \mathrm{m}$ by $500 \mathrm{~nm}$ thick were analyzed with TKD and EDS, prepared from the sample cross section using focus ion beam (FIB). The foils were polished with lowenergy ion milling in order to improve TKD analyses.

The $\mathrm{SZ}_{\mathrm{A} 516}$ adjacent to the interface contains ferrite grains, and Alloy 625 microstructure in the stir zone exhibits austenitic structure with some precipitates. This corresponds with other research conducted on these interfaces [2]. TKD analysis was run on the interface with step sizes down to $6 \mathrm{~nm}$, resulting in much greater spatial resolution than current literature on Ni-steel dissimilar FSW interfaces. Fine precipitates, about $100 \mathrm{~nm}$, were identified within the Ni-based alloy side adjacent to the interface. XEDS and further TKD analysis are ongoing to better characterize the precipitates, their morphology, crystallography and orientation relationships with the matrix. Within the A516 steel side of the interface, small grains, about $300 \mathrm{~nm}$, were observed, as shown in Figure 1. Figure 2 depicts the TKD patterns within the steel side of the interface: a.) at the larger ferrite grains, b.) at the fine $300 \mathrm{~nm}$ grains. Both patterns index as BCC ferrite, commonly seen in martensitic grains because of similarities in crystalline 
structure. The image quality of the latter is worse, suggesting elevated strain, which may be due to the high strain nature of the welding process or from the diffusionless martensitic transformation. Other studies of nickel and steel fusion welds have reported Martensite at weld interfaces due to mixing and diffusion of carbon into the nickel [3]. However, XEDS chemical analyses on this study have shown that the substitutional element region is located on the Ni-625 side of the interface and not at the steel side, where the small $300 \mathrm{~nm}$ BCC grains were observed. In addition, XEDS in Figure 3 depicts $\mathrm{Nb}$ concentrations about $30-50 \mathrm{~nm}$ wide in the $\mathrm{SZ}_{625}$, which may correspond to the particles observed in Figure 1. These microstructural features will be further investigated using nanoindentation and TEM.

\section{References:}

[1] J.R. Rodriguez and A.J. Ramirez, Materials Characterization 110 (2015), p.126-135.

[2] J.R. Rodriguez and A.J. Ramirez, Sci. Technol. Weld. Join. 19 (2014), p.343-350.

[3] B.T. Alexandrov et al, Weld World 57 (2013), p. 39-57.

[4] J.R. Fernandez, 'Microstructural characterization of ASTM A516 - Ni based alloy 625 friction stir welded joints' (Doctoral Dissertation). 2013 p. 72.

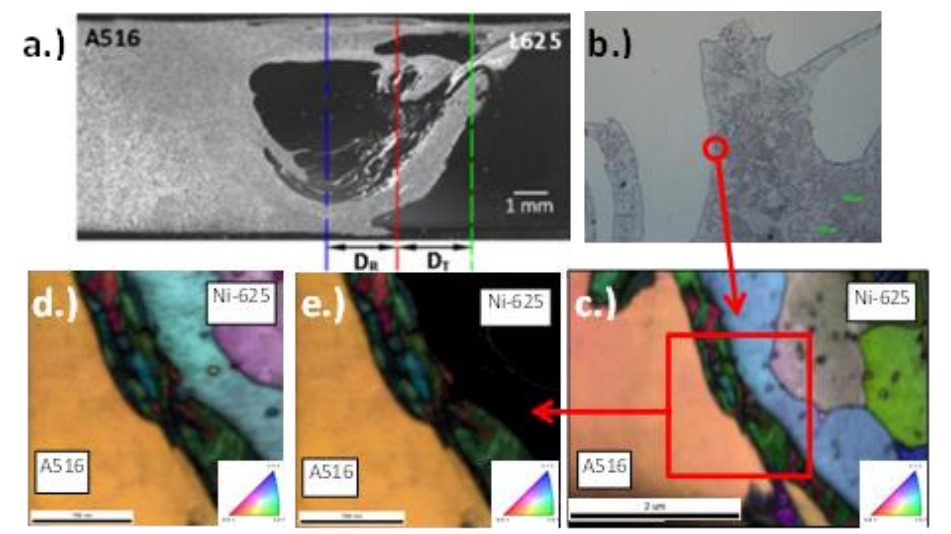

Figure 1. The image a.) shows the FSW stir zone[4]; b.) is an OM image from the interface showing steel on the bottom right. One thin foil was taken from the marked area, and TKD maps were created. c.) and d.) present IPF and IQ maps of both nickel and ferrite; e.) shows ferrite grains only.

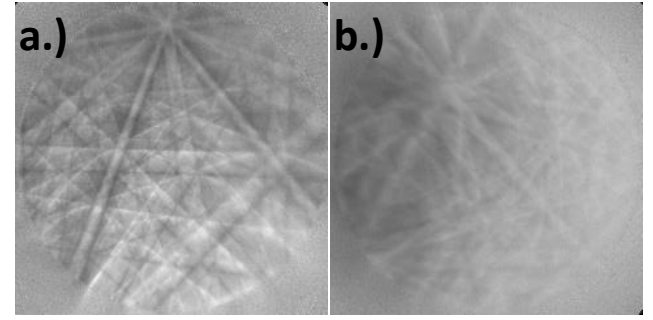

Figure 2. Diffraction patterns of a.) BCC ferrite and b.) fine grains in $\mathrm{BCC}$ adjacent to interface.

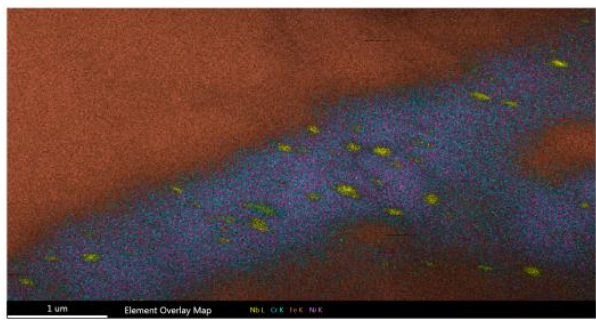

Figure 3. XEDS map at the interface. Fe shown in orange; $\mathrm{Cr}, \mathrm{Ni}$ in blue and magenta; $\mathrm{Nb}$ in yellow. This map shows concentrated areas of $\mathrm{Nb}$ within the $\mathrm{Cr} \mathrm{Ni}$ matrix. 